\title{
A análise do discurso jurídico como caminho para a compreensão da violência contra a mulher
}

\author{
El análisis del discurso jurídico como camino para la comprensión de la \\ violencia contra la mujer
}

\section{The analysis of the legal discourse as a way to understand the phenomenon of violence against women}

Francielli Rubia Poltronieri ${ }^{1}$

\begin{abstract}
Resumo
Neste artigo exploramos os arranjos metodológicos desenvolvidos na pesquisa "Violência doméstica, aparato jurídico e discussões de gênero: as representações de gênero e violência em ações penais da Comarca de Foz do Iguaçu - Paraná”. O objetivo é demonstrar os caminhos percorridos durante a execução da investigação, bem como as mudanças e improvisos necessários para justificar a importância do objeto analisado. Como tratou-se de uma pesquisa com caráter interdisciplinar a opção foi elaborar um estudo descritivo-exploratório, de abordagem qualitativa, prezando pelo aprofundamento dos significados sobre as concepções construídas pelo poder Judiciário com relação à violência de gênero dentro das relações de intimidade, por meio da análise de representações e procedimentos jurídicos. Tal estudo não buscou responder a todas as perguntas que o problema analisado fomenta, no entanto, utilizando-se do conceito de acontecimento elaborado por Michel Foucault pudemos compreender os fatos em suas particularidades. Assim, dentro das limitações impostas, a pesquisa apontou as matrizes formadoras das categorias gênero e violência e revelou as mudanças no contexto jurídico brasileiro com relação aos conflitos de gênero. $\mathrm{O}$ desafio estava em propor uma análise sobre a violência de gênero, adotando estudos já realizados sobre o tema, partindo de uma nova leitura sobre esse tipo de acontecimento e buscando identificar os discursos e as respostas que a sociedade contemporânea, por meio do Poder Judiciário, tem apresentado.
\end{abstract}

Palavras-chave: Violência de Gênero; Poder Judiciário; Processos Criminais; Metodologia Interdisciplinar.

\section{Resumen}

En este artículo exploramos los arreglos metodológicos desarrollados en la investigación "Violencia doméstica, aparato jurídico y discusiones de género: las representaciones de género y violencia en acciones penales de la Comarca de Foz do Iguaçu - Paraná". El objetivo es demostrar los caminos recorridos durante la ejecución de la investigación, así como los cambios e improvisaciones necesarios para justificar la importancia del objeto analizado. Como se trató de una investigación con carácter interdisciplinario la opción fue elaborar un estudio descriptivo-exploratorio, de abordaje cualitativo, previendo por la profundización de los significados sobre las concepciones construidas por el poder judicial con relación a la violencia de género dentro de las relaciones de intimidad, por medio del análisis de representaciones y procedimientos jurídicos. Tal estudio no buscó responder a todas las preguntas que el problema analizado fomenta, sin embargo, utilizando el concepto de acontecimiento elaborado por Michel Foucault pudimos comprender los hechos en sus particularidades. Así, dentro de las limitaciones impuestas, la investigación apunta a las matrices formadoras de las categorías género y violencia y reveló los cambios en el contexto jurídico brasileño con relación a los conflictos de género. El desafío estaba en proponer un análisis sobre la violencia de género, adoptando estudios ya realizados sobre el tema, partiendo de una nueva lectura sobre ese tipo de acontecimiento y buscando identificar los discursos y las respuestas que la sociedad contemporánea, a través del Poder Judicial, ha presentado.

Palabras claves: Violencia de género; Poder Judicial; Procesos Criminales; Metodología Interdisciplinaria.

\footnotetext{
${ }^{1}$ Mestre em Sociedade, Cultura e Fronteira; Secretaria Estadual de Educação do Paraná; Foz do Iguaçu, Paraná, Brasil; francielli.poltronieri@escola.pr.gov.br.
} 


\begin{abstract}
:
In this article we explore the methodological arrangements developed in the research "Domestic violence, legal apparatus and gender discussions: gender representations and violence in criminal actions of the Comarca de Foz do Iguaçu - Paraná ". The objective is to demonstrate the strategies used during the execution of the investigation, as as the changes and improvisations necessary to justify the importance of the analyzed object. As it was a research with an interdisciplinary character, the option was to elaborate a descriptive-exploratory study, of approach qualitative, emphasizing the deepening of the meanings about the conceptions built by the power judiciary regarding gender violence within intimacy relations, through the analysis of representations in legal procedures. This study did not seek to answer all the questions that the problem, but we could understand the facts in their particularities using the concept of an event developed by Michel Foucault. Thus, within the limitations imposed, the research pointed out the formative matrices of the categories gender and violence and revealed the changes in the legal context with regard to gender conflicts. The challenge was to propose an analysis of the violence of adopting studies already carried out on the subject, starting from a new reading about this type of event and seeking to identify the discourses and the responses that contemporary society, through the judicial power, has presented.
\end{abstract}

Keywords: Gender violence; Judicial power; Criminal proceedings; Interdisciplinary methodology.

\title{
1. Introdução
}

Este artigo explora os arranjos metodológicos desenvolvidos para o estudo da "violência de gênero praticada contra as mulheres em suas relações de intimidade". O objetivo da pesquisa realizada foi compreender a violência de gênero dentro das relações de intimidade, seja ela física e/ou psicológica, a partir de representações e procedimentos jurídicos. Para tanto, tornouse necessário percorrer alguns caminhos, entre eles: a realização de análises, por meio do viés interdisciplinar, das principais referências sobre a questão da violência de gênero contra as mulheres no Brasil procurando também construir as representações de gênero e violência por meio da análise de processos criminais. Além disso, as categorias gênero e violência vislumbradas foram inseridas na lógica dos sujeitos envolvidos e nos discursos proferidos por eles, dentro dos processos investigados. Foi necessário, ainda, pesquisar a condição da mulher em um marco histórico de violência, dando ênfase a construção das Leis Maria da Penha (Lei no. 11.340/2006) e do Feminicídio (Lei no. 13.104/2015) para desenvolver o conceito de gênero como uma categoria de análise.

Para alcançar tais objetivos, a opção foi elaborar uma investigação descritivoexploratória, de abordagem qualitativa, prezando pelo aprofundamento dos significados sobre as concepções construídas pelo poder Judiciário. Para tanto, foi considerado que este tipo de pesquisa procura "desenvolver, esclarecer e modificar conceitos e ideias" (GIL, 2008, p.44). Além disso, essa abordagem "responde a questões muito particulares" no campo das Ciências Sociais, com um grau de realidade que não pode ser quantificado. 
A necessidade de apresentar algumas considerações sobre como e onde as fontes utilizadas foram coletadas, as razões que motivaram a coleta de tais documentos e não outros, bem como os aspectos éticos e metodológicos da pesquisa se tornou necessária para este estudo. Em grande medida, a pesquisa foi sustentada por meio da análise documental. Menga Ludke e Marli André (1986), afirmam que a análise de fontes documentais se constitui em uma técnica importante na pesquisa qualitativa, complementando as informações obtidas e desvelando aspectos novos de um tema ou problema. Ademais, a análise documental é uma técnica decisiva para a pesquisa nas Ciências Humanas e Sociais, pois as fontes escritas são, muitas vezes, a base para os trabalhos de investigação. No caso da referida pesquisa, somente por meio da escolha das fontes documentais os objetivos propostos seriam alcançados.

Outrossim, do ponto de vista subjetivo, houve motivações para a escolha do tema proposto, pois ele retorna, a esta pesquisadora, a uma questão muito desconfortável e traz um grande mal-estar. Uma mulher branca, financeiramente independente, graduada e pósgraduada, professora de Sociologia, que encontrou em sua trajetória de vida a violência de gênero em uma de suas formas mais opressoras e limitadoras; sendo vítima de violência doméstica durante longos anos, até o início do ano de 2012, período em que o agressor foi denunciado.

Hoje, procuro atuar contra a violência e principalmente contra o machismo que assola as relações entre homens e mulheres. O fim do relacionamento abusivo se deu quando fugi da residência onde eu era agredida e, em seguida, realizei a denúncia. Esta, gerou um processo penal onde fui assistente de acusação desde o dia 21 de janeiro de 2012 na Comarca do Município de Matinhos, litoral do Estado do Paraná, onde convivíamos. O agressor foi preso em flagrante e permaneceu em cárcere durante vinte e três meses, acusado de lesão corporal e cárcere privado, crimes posteriormente, reconhecidos como tortura, pela forma como foram perpetrados. Em junho de 2015, a primeira sentença foi promulgada. Acusado do crime de tortura, o réu recebeu uma pena de quatro anos em regime aberto e eu, uma indenização mínima, por danos morais. Ele recorreu da sentença e, em 29 de setembro de 2016 o recurso foi julgado no Tribunal de Justiça do Paraná, em parcial provimento e por unanimidade de votos, afastando a fixação do valor mínimo de indenização proposto pelo Ministério Público, e mantendo a pena em quatro anos de reclusão a ser cumprida inicialmente em regime aberto.

Após esse longo período em um relacionamento abusivo, a denúncia e todas as consequências que ela traz, reorganizar minha vida foi necessário. Me reaproximei da família, 
passei por um período de tratamento psiquiátrico e comecei a pensar sobre a aceitação das mulheres frente à situações como esta.

Partindo desta experiência subjetiva e da repetição explícita de submissão e dominação que passei durante uma relação abusiva a necessidade de compreender as causas da violência contra as mulheres e de produzir conhecimento sobre esse tema se configurou em um projeto e, posteriormente, em uma dissertação de mestrado que abordou a violência de gênero praticada contra as mulheres em suas relações íntimas. Dessa forma, a pesquisa realizada durante o curso de mestrado se alimentou da vontade de compreender porque a violência de gênero contra as mulheres e como o poder judiciário aborda as questões relacionadas a este fenômeno.

\section{A busca pelos documentos e a constituição do local de pesquisa}

A referida pesquisa tomou forma por meio da utilização de três processos criminais de violência contra mulheres em suas relações íntimas, processos iniciados entre os anos de 2010 e 2013 e localizados no arquivo de processos da $4^{\mathrm{a}}$ Vara Criminal da Comarca de Foz do Iguaçu. Dessa forma, a análise dos processos crime realizada, dever ser vista apenas um dos conjuntos de análises que poderiam ser realizadas sobre a violência de gênero contra as mulheres.

Os processos penais constituem uma importante fonte documental para análise. Pois nesses documentos todos os procedimentos estão registrados por escrito, desde seu início na esfera policial até sua tradução em fato criminal sendo processado e julgado de acordo com as leis vigentes. Dessa forma, pode-se acompanhar todas as intervenções dos julgadores e jogadores, além dos agentes jurídicos, Wânia Pazinato Izumino (2004) considera a esfera judicial "como uma reprodutora de desigualdades". Nesse sentido, procurou-se observar que tipo de mecanismos são utilizados mais frequentemente na produção dos discursos jurídicos sobre os conflitos de gênero. Além disso, a autora, utilizando-se de Adorno (1994) chama a atenção para a forma como se constrói a pratica jurídica, "calcada numa vontade de saber que se infiltra na vida particular dos envolvidos à procura de elementos que permitam classificar seus atos como aceitáveis ou não" (IZUMINO, 2004, p. 222), permitindo que a desigualdade seja gerada dentro dos próprios processos penais.

As relações descritas durante a investigação se tornaram válidas para definir uma configuração particular: a forma como a violência de gênero contra as mulheres em suas relações íntimas ocorre nos processos atendidos pela Comarca do Município de Foz do Iguaçu, interior do Estado do Paraná, região de fronteira entre Brasil, Argentina e Paraguai. 
Considerando que em cada Comarca, unidade, Tribunal e eventual composição dos órgãos julgadores, as normas mudam, os sentidos migram, e "também mudam conforme o status social do acusado" (ROSA, 2015, p. 25). É importante salientar que as análises apresentadas não foram utilizadas como "signos para descrever, em sua totalidade, a fisionomia de uma cultura" (FOUCAULT, 1987, p. 182) tampouco todos os seus fenômenos. Ainda assim, a análise destes arquivos "comporta [...] uma região privilegiada: ao mesmo tempo próxima de nós, mas diferente de nossa atualidade, [...] é aquilo que fora de nós, nos delimita" (FOUCAULT, 1987, p. 151), sendo importante para as conclusões sobre as representações que o Poder Judiciário constrói sobre gênero e violência, atualmente.

Ademais, para a pesquisa, foi realizada uma analogia do processos criminais a jogos, conforme o que explicita o jurista Alexandre Morais da Rosa (2015), os jogos processuais compreendem uma:

Atividade em contraditório em que há complexa interação entre os jogadores, regulada por lei, na busca do melhor resultado, a ser decidido pelo órgão julgador (singular ou colegiado). Estabelece-se um ambiente de interdependência em que jogadas e atitudes modificam o desenrolar do jogo, o qual conta com destreza, capacidade teórica, sorte e contingência. Há ordem nas jogadas e se pode a cada momento buscar a narrativa do jogo até aquele ponto, alterando, mantendo ou revendo táticas processuais, vinculadas à estratégia (ROSA, 2015, p. 45).

Dessa forma, cada processo passou a ser entendido como um "mecanismo apto à inserção da informação no campo da decisão judicial. É o regime pelo qual o Estado estipula quais as modalidades e a forma de produção da informação" (ROSA, 2015, p. 116, grifos do autor). Para que um acontecimento seja transformado em crime, é necessário que este seja ritualizado/padronizado/normatizado, ou seja, os acontecimentos particulares devem ser caracterizados dentro de um saber, no caso pesquisado, o saber jurídico. Assim, de um lado do campo se dá a construção da versão jurídica do fato, a tradução feita pelos jogadores (os agentes jurídicos - promotores, juízes e técnicos de cada juizado), com base no que ouviram das testemunhas, vítimas e agressores, assim:

[...] no momento em que os atos se transformam em autos, os fatos em versões, o concreto perde quase toda sua importância e o debate se dá entre os atores jurídicos, cada um usando a parte do real que melhor reforce seu ponto de vista. Nesse sentido, é o real que é processado, moído, até que se possa extrair dele um esquema elementar sobre o qual se constituirá um modelo de culpa e um modelo de inocência (CORRÊA, 1983, p. 40).

Do outro lado do campo são apresentados a individualidade e subjetividade dos envolvidos, bem como cada uma das situações vivenciadas por eles. 
Um jogo enquanto categoria universal está presente em um processo penal, afirmou Rosa (2015) “daí que a metáfora da teoria dos jogos pode ser invocada para modelar, de alguma maneira, a matriz teórica de como as decisões podem ser tomadas, partindo-se do estudo dos comportamentos dos jogadores, julgadores e suas recompensas" (ROSA, 2015, p. 26). O campo de relações que caracteriza o julgamento como uma formação discursiva é o lugar onde as simbolizações e os efeitos delas podem ser determinados historicamente, pois o "procedimento penal é a ritualização" (FOUCAULT, 2013, p. 60) da luta entre os envolvidos nos litígios. Assim,

[...] no cenário do jogo processual o discurso promove o deslizamento do imaginário, com a possível fusão de horizontes. Não raro o sujeito ao ocupar a função de jogador ou julgador assume um papel diferente, como se entre o sujeito do mundo [...] e o participante do jogo houvesse um hiato (ROSA, 2015, p. 28).

A busca dos autos criminais da Comarca de Foz do Iguaçu foi iniciada por meio de uma conversa com o Meritíssimo (MM) Juiz Ariel Nicolai Cesa Dias, responsável pelo Juizado Especial de Violência Doméstica e Familiar contra a Mulher, no ano de 2015. Na ocasião, foi acordado que a pesquisa seria realizada nos arquivos físicos do juizado, sendo eu a responsável pelos dados contidos nesses processos, considerando-os segredos de justiça (apesar de serem documentos públicos) e ações penais já encerradas judicialmente. Segundo a advogada e antropóloga Simone Becker (2008) o "segredo de justiça" é visto:

[...] como um dos elementos constitutivos das redes de forças que sustentam as práticas e os discursos jurídicos, enquanto poderes-saberes. Assim, por intermédio da não publicização dos processos judiciais àqueles que deles não participa(ra)m, o Direito representado por seus operadores exerce um duplo controle-vigilância (BECKER, 2008, p. 312).

Nesse sentido, um processo penal é uma história construída sobre a verdade em relação a um determinado acontecimento, é a organização e análise das versões que o constroem e o mesmo "pode cooperar com o controle social" (ROSA, 2015, p. 40). Rosa em seu livro A teoria dos jogos aplicada ao processo penal, chama a atenção para a dimensão coletiva de um processo penal, indicando que um processo deve ser um jogo democrático pelo qual, ao fim, pode-se aplicar uma sanção estatal, entretanto, "se e somente se, cumpridas as normas" processuais (ROSA, 2015, p. 41). Toda partida, independentemente do jogo que está sendo apresentado, segue regras e normas, desse modo, pode-se perceber um jogo como um ritual, dotado de regras e procedimentos padrões, que devem ser seguidos. 
O conjunto de processos judiciais pesquisados data do ano de 2013 e anteriores pois, a partir deste ano todos os processos foram digitalizados, dificultando assim o acesso àquelas pessoas não envolvidas diretamente com os casos. Com esse novo sistema a visualização das peças somente pode ser realizada pelas partes envolvidas e seus representantes legais, por meio de um login e uma senha fornecidos pelo cartório responsável de cada vara criminal. Além disso, por não pertencer ao aparato jurídico, pesquisadores de outras áreas não podem retirar os processos do fórum. A maneira encontrada para realizar a leitura detalhada de cada um deles foi fotografá-los um a um. O espaço disponibilizado para isso foi a sala de audiências do juizado, nos momentos em que ela não estaria sendo utilizada para este fim. No primeiro contato com os documentos, foram selecionados os processos que tratariam do tema proposto para a pesquisa, descartando aqueles gerados por outros crimes.

Atualmente, a Comarca de Foz do Iguaçu atende, além do munícipio sede do Fórum, a cidade vizinha Santa Terezinha de Itaipu. Contando com dezessete Varas Judiciais e vinte e três Juízes de Direito atuantes. As Varas Criminais, foram instaladas, em 1977 (1ª Vara Criminal), 1986 (2 $2^{\text {a }}$ Vara Criminal), 1990 ( $3^{\text {a }}$ Vara Criminal) e 2006 (4 $4^{\text {a }}$ Vara Criminal), que está sob a jurisdição do MM Juiz de Direito Ariel Nicolai Cesa Dias desde o ano de 2012. Sete anos após sua instalação (2013), esta tornou-se especializada e o reconhecida como Juizado Especial de Violência Doméstica e Familiar Contra a Mulher, obedecendo as disposições preliminares da Lei 11.340/2006 (Lei Maria da penha), em seu Art. $1^{\text {o }}$ que dispõe:

Esta Lei cria mecanismos para coibir e prevenir a violência doméstica e familiar contra a mulher, nos termos do $\S 80$ do art. 226 da Constituição Federal, da Convenção sobre a Eliminação de Todas as Formas de Violência contra a Mulher, da Convenção Interamericana para Prevenir, Punir e Erradicar a Violência contra a Mulher e de outros tratados internacionais ratificados pela República Federativa do Brasil; dispõe sobre a criação dos Juizados de Violência Doméstica e Familiar contra a Mulher; e estabelece medidas de assistência e proteção às mulheres em situação de violência doméstica e familiar (BRASIL, 2006).

Antes do reconhecimento de especialização da $4^{\mathrm{a}}$ Vara Criminal os processos penais eram distribuídos entre todas as varas criminais existentes com seus respectivos juízes e promotores. Dessa forma, muitos dos processos localizados no arquivo da Vara eram provenientes de outras Varas Criminais. Foram localizados processos relacionados à crimes como: porte ilegal de armas ou drogas, injúrias e calúnias contra qualquer pessoa, entre outros. Dentre os processos penais localizados, foram descartados, para a pesquisa, todos aqueles em que os crimes não era provenientes de violência familiar ou doméstica contra as mulheres. Assim, foram selecionados, todos os processos onde os crimes foram perpetrados pelo homem 
com o qual a vítima manteve ou mantém um relacionamento íntimo. Todos estes, exemplos que demonstram a incidência da Lei 11.340/2006 (Lei Maria da Penha), conforme informações retiradas dos próprios processos, posteriormente, analisados.

O Juizado especializado abarca, atualmente, todos os processos penais instaurados para a apuração de crimes contra mulheres, como homicídio/feminicídio, tentativa de homicídio/feminicídio, lesões corporais, ameaças, injúrias, calúnias e perturbação do sossego que envolveram relações íntimas ou de parentesco entre agressores e vítimas. Os crimes de violência de gênero praticada contra as mulheres são denunciados em Delegacias da Mulher ou Delegacias comuns. No município de Foz do Iguaçu as denúncias são realizadas diretamente à $6^{\text {a }}$ Subdivisão da Delegacia de Polícia (SDP), ao Centro Integrado de Atendimento - Delegacia da Mulher e do Turista (subdivisão da $6^{\mathrm{a}} \mathrm{SDP}$ ) ou, ao Centro de Referência e Atendimento à Mulher (CRAM). Em alguns casos, as denúncias partem dos órgãos da saúde. Nestes dois últimos, normalmente, a mulher recebe o primeiro atendimento, de saúde ou psicológico e é encaminhada às autoridades policiais. De acordo com as disposições do Capítulo II da Lei Maria da Penha:

Art. 9o A assistência à mulher em situação de violência doméstica e familiar será prestada de forma articulada e conforme os princípios e as diretrizes previstos na Lei Orgânica da Assistência Social, no Sistema Único de Saúde, no Sistema Único de Segurança Pública, entre outras normas e políticas públicas de proteção, e emergencialmente quando for o caso (BRASIL, 2006).

Inaugurada em 1996, a Delegacia da Mulher e do Turista de Foz do Iguaçu atende em horário comercial, das $08: 00 \mathrm{~h}$ as $12: 00 \mathrm{~h}$ e das $14: 00 \mathrm{~h}$ as 18:00h. Uma dificuldade, pois se reconhecermos que os crimes de violência doméstica acontecem, mais frequentemente, após o horário de trabalho e nos finais de semana, este fato deveria influenciar no funcionamento da mesma. O Centro foi inaugurado no ano de 1996, mas somente nos anos 2000 iniciou atendimento em prédio próprio, até então, uma sala na sede da Delegacia da Polícia Civil era utilizada. Hoje, a Delegada chefe Monica Ferraciol conta com o apoio tático de duas escrivãs, quatro investigadoras e duas estagiárias de Direito. Há cerca de dez anos os funcionários (homens), das Delegacias da Mulher, estão sendo substituídos por mulheres, o que, segundo a luta de alguns braços do movimento feminista, auxilia no atendimento à vítima. Nesse sentido, a mulher sente-se menos intimidada ao buscar apoio policial. Nesse sentido Andreia da S. Lima (s/d) considera que:

A Delegacia de Polícia é a porta de entrada da mulher em situação de violência doméstica na rede de atendimento, é a partir do tratamento recebido na Delegacia que 
a mulher se sentirá empoderada, representando contra o agressor (exceto nos crimes de lesão corporal), dando continuidade no processo criminal, requerendo as medidas protetivas previstas na Lei Maria da Penha e buscando auxílio nos Centros de Assistência para sair do ciclo de violência (LIMA, s/d p. 33).

Hoje, muitas mulheres ainda são tratadas com desprezo em delegacias comuns, o que acontecia com maior frequência na década de 1980. Segundo Heleieth Saffioti (1987), “as vítimas já grandemente fragilizadas pela violência sofrida, são objetos de chacotas com base na crença de que mulher gosta de apanhar, ou mulher que apanha agiu errado" (SAFFIOTI, 1987, p. 80, grifos meus). Naquele momento, esta foi a justificativa para a criação das delegacias especializadas no atendimento às mulheres. Ainda assim, a busca pelo entendimento que as instituições sociais devem ter sobre as relações de poder que inferiorizam as mulheres determinam muitas direções de lutas do movimento feminista contemporâneo.

Se, no momento da denúncia e durante a construção do inquérito policial os técnicos responsáveis tratam a mulher agredida enquanto vítima de um crime, ela se sentirá acolhida e segura. Entretanto, nem sempre isso acontece. Em muitos casos de violência doméstica, a mulher é tratada como culpada, como provocadora do ato violento, pois ela é quem poderia ter estimulado a fúria do agressor. Persistem na sociedade contemporânea e em suas instituições, a complexidade e os dilemas inerentes às questões de gênero, estimulados pelas tradições de subjugação da mulher em relação ao homem; essa visão deturpa, inclusive, o aparato jurídico. Infelizmente, mais difícil que mudar a lei é mudar mentalidades. "Muita coisa da lei ainda precisa ser transformada e aplicada efetivamente, mas existe uma vontade e, mais do que isso, uma necessidade de mudar as relações assimétricas entre mulheres e homens" (TELES e MELO, 2003, p. 14). Mudanças que conduzirão à igualdade, à liberdade e à autonomia definitiva para as mulheres.

Durante a pesquisa de campo, a busca e acesso aos processos ocorria com os estagiários e técnicos do juizado que acompanhavam o desenrolar das leituras e cuidadosamente auxiliavam no acesso aos processos, caixa por caixa de arquivo. Assim, dentre os 464 processos penais arquivados entre os anos de 2010 e 2013, a leitura foi realizada de forma decrescente, do último processo arquivado, para os anteriores. Foram fotografados vinte e nove processos, com cerca de cento e quarenta páginas cada um, excluindo imagens de documentos pessoais e comprovantes de residência dos envolvidos. Estes vinte e nove autos foram os últimos a serem arquivados fisicamente pois, logo após a criação do juizado especial - no ano de 2013 - os processos passaram a ser arquivados digitalmente. 
Após a organização das imagens, foi realizada uma leitura mais detalhada de cada um dos documentos, com o objetivo de optar quais deles seriam utilizados. Foram selecionados: um processo referente aos crimes de injúria e ameaça contra uma mulher, onde um menor de idade, filho dos envolvidos, foi testemunha da violência, neste caso, o casal já estava separado judicialmente. Um segundo processo referente aos crimes de ameaça e lesão corporal leve contra uma mulher onde, os envolvidos não deixaram de manter o relacionamento (casamento) durante o processo - nestes, a sentença foi condenatória -. Por fim, um terceiro processo no qual o ex-marido da vítima foi acusado dos crimes de ameaça e lesão corporal, o casal já estava separado antes dos crimes em questão e, segundo relatórios, a vítima já havia sofrido outros tipos de violência doméstica, não denunciados, que geraram a separação, - neste, o réu foi absolvido.

Os motivos que levaram a seleção destes e não de outros processos foram de os crimes descritos serem os exemplos mais comuns de violência de gênero contra as mulheres em suas relações íntimas ou familiares, crimes considerados tão "banais", que podem ser tratados como algo que faz parte da vida de um casal, pela sociedade. A construção dos processos selecionados, por mais que não pertencessem a um Juizado Especial foi baseada na Lei Maria da Penha (LMP), uma lei que alterou a forma como as mulheres vítimas do crime de violência doméstica devem ser atendidas. Diversas pesquisas, como por exemplo o artigo publicado na Revista Intelletto por Cavaquini e Santana (2016), analisaram como se dá o tratamento aos crimes de violência contra as mulheres antes e após a promulgação da Lei 11.340/2006.

Dentre os documentos acessados, nenhum deles apresentava crimes como feminicídio. Nos três processos houve apelação da sentença, em dois deles, partindo do réu e no último partindo do Ministério Público. Com relação à forma de arquivamento, os documentos eram divididos em pastas coloridas, rosa para aqueles em que houve apelação à sentença e azul para aqueles em que a sentença proferida pelo(a) juiz(a) foi aceita.

Processos Penais apresentam características semelhantes que podem ser encontradas durante sua construção, sendo que esta segue normas e a juntada de documentos se dá de forma padronizada. De acordo com o jurista Alexandre Morais da Rosa (2015, p. 20), um processo penal é "algo que se compreende artesanalmente, no contexto em que acontece. [...] É uma prática artesanal e não um modelo universal, pela qual a facticidade ganha importância, ou seja, não é carente de realidade, analisando-se a convenção jurídica em vigor." Nesse sentido, enquanto fontes de pesquisa, estes documentos apresentam característica em particular, pois 
são únicos, construídos na individualidade dos envolvidos e em situações vivenciadas somente por eles.

\section{A busca por uma metodologia que permitisse "ao objeto falar"}

Para a pesquisa optou-se pelo uso da noção de acontecimento formulada por Michel Foucault (1987), de maneira que fosse possível compreender como os fatos se desencadeiam e como se convertem em acontecimentos. Um acontecimento, para Foucault, não é uma totalidade, é uma descrição e toda descrição é seletiva, implica escolhas dos elementos que serão narrados em detrimento dos que não serão. Assim, cada acontecimento faz parte de uma trama e só faz sentido dentro dela, permitindo a visão de alguns aspectos de sua realidade. Nas palavras de Wânia Pazinato Izumino (2004):

Essa possibilidade de múltiplas leituras sobre o mesmo fato, entendida como a leitura de acontecimentos, define a possibilidade de focalizar o fato de diferentes ângulos sem que, com isso, o fato original venha a ser alterado. Permite também que se conheça a partir do modo como as versões vão sendo apresentadas e agregadas ao relato inicial, os mecanismos que atuam na criminalização dos casos que envolveram conflitos de gênero (IZUMINO, 2004, p. 69).

Após a seleção dos documentos, foi iniciada uma pesquisa histórico/documental, como forma de construir interpretações - por meio da desconstrução dos mesmos - de registros e fatos históricos locais que serviriam para a constituição dos esboços das instituições e dos sujeitos sociais contemporâneos. Na perspectiva de Jacques Le Goff (1995), tal influência pode ser descrita, sob um de seus aspectos, na noção de desestruturação de um documento. Assim, não foi o bastante, apenas uma interferência subjetiva na seleção documental; foi necessário desconstruí-los para apreender suas condições de produção. Nesse sentido, foi "preciso pesquisar a partir da noção de documento/monumento, proposta por Michel Foucault em $A$ arqueologia do saber" (LE GOFF, 1995, p. 54). De acordo com o próprio Foucault (1987),

[...] em nossos dias, a história é o que transforma documentos em monumentos e que desdobra, onde se decifravam rastros deixados pelos homens, onde se tentava reconhecer em profundidade o que tinham sido, uma massa de elementos que devem ser isolados, agrupados, tornados pertinentes, inter-relacionados, organizados em conjuntos. Havia um tempo em que a arqueologia, como disciplina dos monumentos mudos, dos rastros inertes, dos objetos sem contexto e das coisas deixadas pelo passado, se voltava para a história e só tomava sentido pelo restabelecimento de um discurso histórico; que poderíamos dizer, jogando um pouco com as palavras, que a história, em nossos dias, se volta para a arqueologia - para a descrição intrínseca do monumento (FOUCAULT, 1987, p. 8). 
Edgardo Castro (2016, p. 24), trabalha a noção de documento/monumento como uma forma de fazer história, uma forma de elevar o que as pessoas disseram ou dizem ao estatuto de acontecimento, caracterizando uma modalidade de análise histórica. Assim, o que foi dito instaura uma realidade discursiva e sendo, o ser humano, um ser discursivo, criado pela linguagem, a Arqueologia serve de instrumento para desvendar como os sujeitos constroem sua própria existência.

Após a desconstrução e análise dos processos, por meio do balanço bibliográfico foi possível perceber que grande parte dos estudos sobre a violência de gênero contra as mulheres são realizados de uma maneira muito distante, entre as pesquisadoras, mulheres que provavelmente, acreditam não estarem sujeitas às relações de poder que a violência de gênero impõe e as mulheres que sofrem ou sofreram algum tipo de violência, mas esse não foi o caso. Pela proximidade e intimidade desta pesquisadora com o objeto e o tema da pesquisa, o conceito de subjetividade foucaultiano, foi eleito, como um dos instrumentos para as análises e para a compreensão dos sujeitos envolvidos e construídos dentro dos processos criminais pesquisados na $4^{\mathrm{a}}$ Vara Criminal da Comarca de Foz do Iguaçu. Outrossim, como Renato Rosaldo (2000) aponta, em vez de falar dos crimes de maneira geral, considerou-se a posição de cada sujeito dentro de determinado campo de relações sociais, com o objetivo de captar a experiência subjetiva de cada um deles.

Para tanto, a caracterização dos discursos subjacentes às práticas jurídicas e as análises sobre as concepções elaboradas pelo poder judiciário em relação as questões de gênero e de violência nos processos foram iniciadas. Nesse sentido, a subjetividade foi compreendida como uma construção histórica, localizada no tempo e no espaço, a partir das relações dos saberes já disponíveis para a construção de um sujeito - réu e vítima.

Utilizando as premissas propostas por Michel Foucault, como instrumentos de análise das práticas discursivas dos envolvidos nos crimes e seus respectivos interlocutores, a pesquisa foi voltada à construção das representações de gênero e de violência elaboradas pelo judiciário, analisando, sobretudo, as subjetividades e as definições conceituais no interior das peças, reconstituindo o julgamento e os trâmites de cada um dos processos como um conjunto de atitudes e práticas sociais - um jogo - onde as regras do Direito são colocadas em prática. Essa analogia - dos trâmites processuais ao jogo - vem do conceito de Wittgenstein, Von Neumann e Morgenstern, citados por Clifford Geertz (2008) onde os "atos intencionais seguem regras" e, onde o comportamento social é visto "como uma manobra recíproca para obter resultados distributivos." (GEERTZ, 2008, p. 40 grifos do autor). Robles (2010), citado por Rosa (2015), 
por sua vez, "sustenta que o Direito é comparável aos jogos já que em ambos aparecem como comportamentos de cooperação, competência, luta e conflito, em que o resultado não depende somente da sorte, mas da performance dos jogadores em face ao Estado Juiz" (ROSA, 2015, p. 23).

Durante a primeira fase de análises os princípios da organização processual foram explicitados, evidenciando as características da justiça contemporânea, interpretada enquanto um jogo, dotado de regras e normas, construído por equipes e jogadores e compreendendo os fatos sociais "como um conjunto de jogos [...] como uma extensa pluralidade de convenções e procedimentos vários - mundos fechados e sem ar, de jogadas e contra jogadas, a vida em règle" (GEERTZ, 2008, p. 43). Dessa forma a pesquisa descreveu o discurso como um produto que se constitui a partir de determinadas condições sociais e o definiu enquanto prática que obedece a regras sociais, pois o que está em pauta na análise foucaultiana dos discursos é a articulação acerca do que pensamos, dizemos e fazemos caracterizando determinado período, uma vez em que o conhecimento discursivo se transforma nos acontecimentos históricos.

Em sua fase arqueológica, Foucault enfatizou diferentes vertentes (filosófica, econômica, científica - já se utilizando de uma prática interdisciplinar), para compreender as condições de emergência dos discursos. Para isso, utilizava recortes históricos muito precisos, mas que não se destinavam a "reduzir a diversidade dos discursos nem a delinear a unidade que deve totalizá-los, mas sim a repartir sua diversidade em figuras diferentes” (FOUCAULT, 1987, p. 183) - na pesquisa, os processos apresentados serviram como um recorte geográfico e temporal e foram utilizados para:

[...] descrever não somente a maneira pela qual os diferentes saberes se determinaram a partir da constituição de novos objetos que emergiram num certo momento, mas como eles se relacionam entre si e desenham de maneira horizontal uma configuração epistêmica coerente (REVEL, 2005, p. 16).

Portanto, dentro dos discursos produzidos pelos sujeitos envolvidos em crimes, as comparações realizadas através da arqueologia não tem um efeito unificador, mas multiplicador de determinado fenômeno, segundo Foucault (1987). Além disso, nas análises dos discursos jurídicos a respeito dos crimes de violência de gênero contra as mulheres a opção foi não realizar análises privilegiando uma visão vitimista relacionada às mulheres que buscam a justiça, mas demonstrar essa busca como uma forma de resistência.

O conhecimento dos procedimentos técnicos de elaboração de um processo criminal tornou-se necessário, principalmente, pela necessidade de familiarização com o "jurisdiquês" 
e com seus muitos termos e procedimentos, por isso a pesquisa apresentou uma descrição não exclusivamente jurídica dos processos, uma linguagem científica, mas não técnica, como um advogado ou jurista apresentaria. Afinal, uma Cientista Social/professora promoveu uma tentativa de análise dos discursos jurídicos. E, apesar de o discurso jurídico se utilizar de uma linguagem neutra, objetiva e universal, suas práticas são construídas por meio de determinadas representações sociais e por valores que induzem a determinadas materialidades. Nesse sentido, o resultado processual não depende da performance, exclusiva, de um dos jogadores, "mas decorre da interação das estratégias e táticas utilizadas no limite temporal do processo, até porque a valoração do desemprenho é feita do lugar do órgão julgador (ROSA, 2015, p. 31). Portanto e desse modo, a sentença não será, em hipótese alguma, a verdade sobre determinado acontecimento, mas o esgotamento do saber jurídico sobre ele. Nesse sentido, Fonseca (2012) explicitando Foucault, demonstra que a pena/sentença é parte de um procedimento criminal e, além disso, o objeto de execução da pena é a lei. "E será justamente em referência à lei que o seu significado político poderá aparecer claramente" (FONSECA, 2012, p. 127).

Toda essa busca foi necessária para que fosse possível compreender quais seriam as peças de maior interesse para análise do discurso jurídico sobre esse tipo de conflito de gênero. Assim, as peças que apresentaram intervenções de agentes jurídicos tiveram especial atenção, pois os momentos em que a justiça é chamada a intervir nos acontecimentos, são momentos de decisão, onde as etapas, a história e a construção de uma verdade constitui-se por diferentes versões de um mesmo acontecimento.

\section{A descrição dos jogos processuais e o uso do referencial teórico}

Um jogo processual pode se realizar de duas maneiras diferentes. Uma delas é aquela onde os envolvidos no crime, expõem seus dramas particulares, essa maneira ainda não pode ser interpretada enquanto um jogo. Entretanto, a outra versão - a que foi analisada durante a referida pesquisa - é aquela construída pelos jogadores e julgadores, aqueles que elaboram a versão jurídica de um acontecimento (as regras do jogo) onde cada gesto, palavra, silêncio ou comportamento são traduzidos em artigos, qualificadoras, agravantes e atenuantes de um crime. Além disso, deve-se considerar que em um jogo processual as regras são impostas pelo Estado e sustentadas pelos jogadores, são essas regras que vão delimitar o tempo desde a denúncia até o trânsito em julgado, bem como o espaço onde o jogo será realizado. 
O segundo momento das análises realizadas partiu do âmbito não discursivo dos acontecimentos, onde, estes foram compreendidos enquanto práticas sociais inseridas nas relações de poder. Assim, se pode compreender:

[...] o enunciado na estreiteza e singularidade de cada situação; de determinar as condições de sua existência, de fixar seus limites da forma mais justa, de estabelecer suas correlações com os outros enunciados a que pode estar ligado, de mostrar que outras formas de enunciação exclui (FOUCAULT, 1987, p. 31).

Considerando o "saber [...] como materialidade, como prática, como acontecimento" (MACHADO, 2015, p. 27). Nesse sentido, o saber jurídico foi compreendido como um saber político, pois este serviu como um instrumento de normatização/dominação das instituições sobre os sujeitos. Assim, entende-se que todo campo onde o poder é exercido é um local de formação de um saber ou de uma verdade. Além disso, por este ser um fenômeno social complexo, que exige uma complementaridade de disciplinas para compreendê-lo, e pelo "caráter dialético da realidade social" (FRIGOTTO, 2008, p. 43), a necessidade da prática interdisciplinar da pesquisa, foi fundamentada. Daniela E. de Souza Mossini (2010, p. 203) afirma que a abordagem interdisciplinar de um fenômeno jurídico, realizada em conjunto com as outras Ciências Sociais, pode ser considerada a única forma pela qual o Direito assume sua verdadeira condição de ciência, uma vez que o objeto relações sociais é comum para estes campos do saber.

Em relação ao referencial teórico, foram buscadas as matrizes formadoras de cada categoria pertencente às unidades de análise, ou seja, as peças judiciais, construindo a genealogia dos conceitos como base teórica para as análises dos discursos. Entre eles foram conceituados: violência doméstica conforme o conceito apresentado pelas autoras Maria Amélia de Almeida Teles e Mônica Melo (2003), Emília Fernandes (2003), Carmem Heim Campos e Saulo de Carvalho (2006); gênero categorizado por Joan Scott (1995) e Judith Butler (2003), além da utilização de Wânia Pazzinato Izumino (2004). Representações segundo Clifford Geertz (2008) e Mary Rangel (2003). Os exemplos apresentados durante a pesquisa se referiam às relações de poder estabelecidas entre homens e mulheres, cotidiana e atualmente.

Dos vinte e nove autos criminais fotografados e analisados, três deles foram eleitos para a fase genealógica (a desconstrução do documento) da pesquisa. Não pela grandeza dos casos, mas por serem os exemplos mais comuns de violência contra mulheres de acordo com as fontes documentais acessadas. Casos pouco comoventes que envolveram mulheres brasileiras, vítimas de seus parceiros ou ex-parceiros íntimos, homens, também brasileiros. Quanto à 
sistematização dos processos, o trabalho foi realizado por meio do enfoque analítico discursivo proposto por Michel Foucault, especificamente, as particularidades do método Genealógico, sem excluir as especificidades da Arqueologia.

O início das análises dos processos ocorreu a partir de sua inserção na esfera policial. Isto quer dizer que para cada um dos acontecimentos analisados, a denúncia realizada à polícia, por meio do Boletim de Ocorrência, é o ponto de partida, pois é a partir dela que os acontecimentos deixam de estar no âmbito privado e passam a ser normatizados ou judicializados. Descrevendo os arquivos, procurou-se desenvolver suas possibilidades de construção social. O objetivo, ao realizar essa desconstrução, foi "buscar compreender as suas regras, suas práticas, suas condições e seu funcionamento" (REVEL, 2005, p. 18), ou seja, compreender as regras do jogo.

Sendo o campo de ação do saber jurídico algo constituído historicamente, baseado em práticas sociais anteriores à sua construção, pode-se compreender a normatização de um ato, enquanto criminoso ou ilegal, somente dentro das normas impostas por este saber, dentro de um processo de representação de um fenômeno, como considerou Clifford Geertz (2008). Esta representação de um acontecimento torna-o um ato ilícito, passível de relações processuais. "Trata-se, basicamente, não do que aconteceu, e sim do que aconteceu aos olhos do Direito; e se o Direito difere, de um lugar ao outro, de uma época a outra, então o que seus olhos veem também se modifica" (GEERTZ, 2008, p. 259). Nesse sentido, "as regras dependem da convenção Estatal, ou seja, da elaboração de produção normativa", são produtos convencionais tanto que, estrutura e funcionamento de um processo penal variam em cada país (ROSA, 2015, p. 25). Assim, todas essas regras "parecem uma das formas pelas quais nossa sociedade definiu tipos de subjetividade, formas de saber e, por conseguinte, relações entre o homem e a verdade que merecem ser estudadas" (FOUCAULT, 2013, p. 21), por meio de olhares diferentes em cada época.

Cada um dos documentos selecionados foi trabalhado de maneira a reconstituir os acontecimentos em questão, em sua singularidade (partindo de uma maneira específica de imaginar a realidade - a judicialização de um fato), evitando estabelecer uma continuidade histórica com outros eventos, pois "a genealogia trabalha a partir da diversidade e da dispersão, do acaso dos começos e dos acidentes: ela não pretende voltar ao tempo" (REVEL, 2005, p. 52) para reconstruir seus objetos de análise, dando a eles significado; isto significa dizer que a proposta genealógica não busca no passado acontecimentos singulares, mas que ela se coloca no tempo presente. Assim: 
a análise em termos de poder não deve postular, como dados iniciais, a soberania do Estado, a forma da lei ou a unidade global de uma dominação; estas são apenas e, antes de mais nada, suas formas terminais. Parece-me que se deve compreender o poder, primeiro, como a multiplicidade de correlações de força imanentes ao domínio onde se exercem e constitutivas de sua organização; o jogo que, através de lutas e afrontamentos incessantes as transforma, reforça, inverte; os apoios que tais correlações de força encontram umas nas outras (FOUCAULT, 1988, p. 102).

Essas relações de forças, exemplificadas por Foucault (1988), podem ser verificadas nas práticas jurídicas, inclusive, nos acontecimentos relacionados nesta pesquisa. Como já sugerido em diversos outros trabalhos, em casos de conflito de gênero, a adequação de vítimas e agressores à papeis sociais gera desigualdades, inclusive no acesso à justiça (CORRÊA, 1983, ARDAILLON e DEBERT, 1987). Esses papeis também estão "relacionados à família e ao casamento, considerados como instituições que devem ser protegidas, de acordo com o interesse social" (IZUMINO, 2004, p. 222, grifos da autora), o interesse social a que se refere a autora, sobrecarrega as mulheres que buscam a justiça. Nesse sentido, quando uma mulher, que sofre violência doméstica, chega a denunciar o agressor, esta é uma (talvez a única) alternativa em que ela prevê possíveis mudanças na relação em que vive. Contudo, nem sempre a denúncia ou o processo judicial são sinônimos do desejo de afastar-se do agressor, estas podem ser apenas tentativas de coibir a violência sofrida, como foi possível perceber durante a descrição de um dos processos selecionados.

Com relação à descrição dos processos e a utilização dos nomes dos envolvidos, acredita-se que a supressão dos nomes, as discussões metodológicas sobre tal feito e a exigência do interesse público nos casos analisados, necessariamente, convergem para o respeito à intimidade dos sujeitos envolvidos, tal como sugere José Roberto Goldim (2004) em suas reflexões a respeito de ética nas pesquisas. Além disso, nesse momento, além de pensar no rigor acadêmico que se é esperado, a minha subjetividade em relação aos acontecimentos prevaleceu. Me veio à mente o sentimento de uma mulher que denuncia um crime de violência doméstica.

Pois, muitas mulheres não denunciam seus agressores por vergonha, pelo medo da discriminação ou pelo possível estigma social que podem vir a carregar, além de sentir o peso dos julgamentos que os grupos sociais tendem a fazer. Entre outros sentimentos que assolam a mente de uma mulher que sofre qualquer tipo de violência, existe, principalmente, a vergonha da agressão que sofreram ou sofrem, em um ambiente compreendido como seguro e de este ato ter sido realizado por seu parceiro, uma pessoa com quem ela escolheu dividir dúvidas, medos, angústias, enfim, a vida. Ademais, há entre as mulheres, um sentimento de impunidade. Foi por estes motivos que a necessidade de não expor os nomes das vítimas, resguardando sua 
privacidade, e impossibilitando o reconhecimento das mesmas se tornou necessária durante a escrita.

O apoio técnico, aos jogos, inicialmente é realizado pelas autoridades policiais, delegados, escrivães e investigadores e, em seguida, pelos funcionários da justiça, entre eles os técnicos da secretaria do juizado (responsáveis pela digitação de atas e certidões, pelo encaminhamento das mesmas aos setores responsáveis, pelos relatórios de citação e pelas pesquisas documentais junto ao sistema judiciário, como, por exemplo, o Relatório de Vida Pregressa do indiciado), além dos oficiais de justiça (responsáveis pelas intimações das partes). Estes jogadores são o apoio tático dado aos jogos, eles são os responsáveis por toda a infraestrutura necessária para que o jogo ocorra dentro da normalidade. Nesse sentido, é possível descobrir "não uma configuração ou uma forma, mas um conjunto de regras que são imanentes a uma prática e a definem em sua especificidade" (FOUCAULT, 1987, p. 53). Ainda, segundo Foucault (1987), pode-se avaliar até que ponto esse discurso silencioso modifica o acontecimento inicial, pois, quem profere este discurso é quem enquadra o objeto/acontecimento ao sistema, adequando e interpretando os discursos dos envolvidos nos crimes ao jogo, sua forma de transcrever os acontecimentos particulares é uma reelaboração de cada um deles dentro do saber jurídico, normatizando-os, "criando assim, um sentido de justiça determinado" (GEERTZ, 2008, p. 260).

Na rotina de um processo judicial, pode-se perceber que estes auxiliares técnicos são invisíveis aos olhos das partes envolvidas no jogo, mas, importantes aliados do saber/poder jurídico em sua utilização prática. Michel Foucault (2013) nos demonstra que é isso que os detentores do saber propõem "a constituição histórica de um sujeito [...] através de um discurso tomado como um conjunto de estratégias que fazem parte das práticas sociais" (FOUCAULT, 2013, p. 20). Nesse sentido, uma história externa do acontecimento pode ser elaborada, pois esses jogadores, estão situados a uma distância perceptiva ótima cujos limites demarcam a parcela de informação pertinente, utilizando-se de instrumentos que podem modificar as informações do acontecimento em questão (FOUCAULT, 1987, p. 59).

Por meio dos processos descritos e de outros processos não apresentados na pesquisa, foi possível perceber que mulheres de todas as classes sociais, raças e etnias, religiões e culturas sofrem com a violência doméstica, um tipo de violação de direitos. Dessa forma, é possível compreender que falar em violência de gênero contra as mulheres é traduzir em palavras evidências numéricas. 
No Brasil, como em outros lugares do mundo, todos os dias mulheres são agredidas, física e psicologicamente. "Setenta por cento das agressões físicas dolosas que vitimam mulheres são da responsabilidade do marido/amante/companheiro" (MORAES, NAVES, 2002, p. 10). Entretanto, segundo Saffioti (2002), “não se pode afirmar, sobre nenhuma parte do mundo, que o fenômeno violência doméstica apresenta uma incidência de $25 \%$ ou $38 \%$ contra mulheres" (SAFFIOTI, 2002, p. 34). Pois, para a autora, além das dificuldades em coleta de dados na rede hospitalar, na polícia e nos centros de atendimento, enfrenta-se o fato de que mulheres escondem as agressões de suas próprias famílias, quem dirá de um pesquisador.

\section{Conclusões}

Temáticas tão complexas quanto a violência de gênero contra as mulheres exigem aprofundamento teórico interdisciplinar e sensibilidade por parte daqueles que atuarão nessa área. Analisar a frieza dos papeis, a "letra fria da lei" não foi uma tarefa fácil. Nesse sentido compreender os discursos, por meio de petições e atas tornou-se um desafio. Compreender a realidade de uma mulher que sofre/sofreu violência doméstica é um desafio para toda a sociedade, inclusive para as instituições legais e seus representantes, socializados em um ambiente machista, onde homens/heterossexuais/brancos ainda são considerados hierarquicamente superiores a todas as "minorias sociais" que são diferentes deste padrão a ser seguido.

“Ouvir" o que o objeto pesquisado "tem a dizer" é uma das formas mais promissoras de atingir os objetivos propostos pois, dessa forma, a metodologia será adaptada ao objeto e não o contrário, percebe-se que a grande dificuldade nas pesquisas acadêmicas advém de o pesquisador buscar adaptar o objeto a uma sequência metodológica pronta. Foi possível perceber por meio da análise documental que diferentes tipos de processos judiciais podem servir a diferentes tipos de pesquisa, sendo possível extrair deles análises variadas e sobre grupos ou categorias sociais diversos. Entretanto, essas diferentes pesquisas têm em comum o fato de trabalharem com a interpretação da palavra escrita a fim de discorrer sobre a construção do discurso empreendido por determinados grupos. No caso da pesquisa apresentada neste estudo, considerou-se a posição de cada sujeito dentro de determinado campo de relações sociais (o campo jurídico), com o objetivo de captar a experiência subjetiva de cada um deles por meio dos discursos proferidos.

É possível, ainda, classificar o tipo de pesquisa feita a partir da utilização de processos judiciais, a primeira forma de definição é a pesquisa documental. Pois processos são 
documentos históricos e oficiais, e o trabalho com esses documentos traz, ao menos, duas implicações metodológicas: a questão do poder e a da interpretação. Estes questionamentos surgem principalmente quando se trabalha qualitativamente com os dados (como pode-se perceber no estudo apresentado), quando a preocupação está em buscar a lógica e os códigos que estão informando as palavras para inferir sobre representações de sujeitos ou instituições específicos.

É necessário compreender que a construção de uma pesquisa na área das Ciências Sociais pode apresentar características semelhantes. Michaelis (1998, p. 1368), define método como sendo o "conjunto dos meios dispostos convenientemente para alcançar um fim e especialmente para chegar a um conhecimento científico ou comunicá-lo aos outros". Entretanto, é preciso avançar na forma de pensar e ressaltar que o método, juntamente com os objetivos, serve para dar rumo ao trabalho a ser desenvolvido e que, por mais, que os métodos sejam padronizados, as pesquisas não são realizadas desta forma, especialmente se tratando de pesquisas com caráter interdisciplinar. O interesse do investigador deve estar claro, bem discriminado, uma vez que a parte metodológica só poderá fazer sentido, se adequada aos objetivos propostos.

Uma pesquisa científica é uma prática artesanal, assim como a construção de um processo penal, não segue um modelo universal de investigação ou metodologia. Nesse sentido, estas, apresentam características particulares, são únicas, construídas de acordo com a subjetividade na escolha do tema e não podem ser consideradas a totalidade sobre determinado objeto de pesquisa. Uma pesquisa é uma descrição e toda descrição é seletiva, implica nas escolhas dos elementos que serão narrados em detrimento dos que não serão. Assim, cada pesquisa faz parte de uma trama e adquire sentido dentro dela, permitindo, dessa forma, a visão de alguns aspectos da realidade analisada.

\section{Referências}

ARDAILLON, Danielle; DEBERT, Guita. Quando a vítima é mulher. Análise de julgamentos de crimes de estupro, espancamento e homicídios. Brasília: CNCM, 1987. (Obra Completa)

BECKER, Simone. Dormientibus non-socurrit jus! (O direito não socorre os que dormem!): Um olhar antropológico sobre ritos processuais judiciais (envolvendo o pátrio poder/poder familiar) e a produção de suas verdades. 2008. 337f. Tese (Doutorado em Antropologia Social) - UFSC, Florianópolis, 2008. (Tese) 
BRASIL. Lei 11.340/2006 Lei Maria da Penha, de 7 de agosto de 2006 (a). Disponível em: http://www.planalto.gov.br/ccivil_03/_ato2004-2006/2006/lei/111340.htm. Acesso em: 05 maio 2015. (Legislação em Formato Digital)

BUTLER, Judith P. Problemas de gênero: feminismo e subversão da identidade. Tradução Renato Aguiar. Rio de Janeiro: Editora Civilização Brasileira, 2003. (Obra completa)

CAMPOS, Carmen Hein; CARVALHO, Salo de. Violência doméstica e Juizados Especiais Criminais: analise a partir do feminismo e do garantismo. In: Revista Estudos Feministas. Florianópolis. Maio/agosto 2006. Disponível em:

http://www.scielo.br/pdf/ref/v14n2/a05v14n2.pdf. Acesso em: 15 mar. 2017. (Artigo em periódico digital)

CASTRO, Edgardo. Vocabulário de Foucault: Um percurso pelos seus temos, conceitos e autores. Trad. Ingrid Muller Xavier. 2 ed. Belo Horizonte: Autentica Editora, 2016. (Obra Completa)

CAVACHINI, Juliana da Costa. SANTANA Cláudio. Et al. In: Revista Científica Intelletto v.1, n. 3, Espírito Santo: 2016. (Artigo em periódico digital).

CORRÊA, Mariza. Morte em família. Representação jurídica dos papeis sexuais. São Paulo: Graal, 1983. (Obra Completa)

FERNANDES, Emília. In: BRASIL, Secretaria Especial de Políticas para as Mulheres: Programa de Prevenção, Assistência e Combate à Violência Contra a Mulher - Plano Nacional: diálogos sobre violência doméstica e de gênero: construindo políticas públicas. Brasília: A Secretaria, 2003. (Plano nacional de políticas públicas em formato digital)

FRIGOTTO, Gaudêncio. A interdisciplinaridade como necessidade e como problema nas Ciências Sociais. In: Ideação v. 10, n.1, $1^{\text {o }}$ semestre de 2008. (Artigo em Periódico Físico)

FONSECA, Marcio Alves da. Michel Foucault e o direito. 2 ed. São Paulo: Saraiva, 2012. (Obra completa).

FOUCAULT, Michel. A Arqueologia do saber. Trad. Luiz Felipe Baeta Neves. 3 ed. Rio de Janeiro: Forense-Universitária, 1987. (Obra Completa)

(Obra Completa)

, Michel. A verdade e as formas jurídicas. 4 ed. Rio de Janeiro: Nau, 2013.

, Michel. História da sexualidade I: a vontade de saber. 9 ed. Rio de Janeiro:

Graal, 1988. (Obra Completa)

GEERTZ, Clifford. $O$ saber local: novos ensaios em antropologia interpretativa. Trad. Vera Mello Joscelyne. 10 ed. Petrópolis, Vozes: 2008. (Obra Completa)

GIL, Antônio Carlos. Como elaborar projetos de pesquisa. 4 ed. São Paulo: Atlas, 2008. (Obra Completa) 
GOLDIM, José Roberto. Ética e pesquisa em Antropologia. In: VICTORA, Ceres; OLIVEN, Ruben George et al. (Orgs.). Antropologia e ética. O debate atual no Brasil. Niterói: EdUFF. 2004. p.163-168. (Capítulo de Livro)

IZUMINO, Wânia Pazinato. Justiça e violência contra a mulher: o papel do judiciário na solução dos conflitos de gênero. 2 ed. São Paulo: Annablume: FAPESP, 2004. (Obra Completa)

LE GOFF, Jacques. As Mentalidades: Uma história ambígua. In: LE GOFF, Jacques; NORA, Pierre. (Dir.). História: Novos Objetos. Rio de Janeiro: Francisco Alves, 1995. (Capítulo de Livro)

LIMA. Andreia da S. Considerações sobre o atendimento pela autoridade policial no âmbito da lei Maria da Penha. In: Violência Doméstica e Familiar contra a mulher - Revista do Nuden. 1 ed. Disponível em:

http://www.defensoria.sp.gov.br/dpesp/repositorio/41/Revista_viol\%C3\%AAncia\%20dom\% C3\%A9stica.pdf. Acesso em: 03 mar 2015. (Artigo em Periódico Digital)

LUDKE, Menga; ANDRE, Marli E.D.A. Pesquisa em educação: abordagens qualitativas. São Paulo, EPU, 1986. (Obra Completa)

MACHADO, Roberto. Por uma genealogia do poder. In. FOUCAULT, Michel. Microfísica do poder. 3 ed. Rio de Janeiro: Paz e Terra, 2015. p. 07-23. (Capítulo de Livro)

MICHAELIS. Moderno dicionário da língua portuguesa. São Paulo: Companhia Melhoramentos, 1998. (Obra completa)

MORAES, Maria L. Q. de. NAVES, Rubens. (orgs.) Advocacia pro bono em defesa da mulher vítima de violência. Campinas: Unicamp. 2002. (Capítulo de Livro)

MOSSINI, Daniela] Emmerich de Souza. Ensino Jurídico: história, currículo e interdisciplinaridade. 2010. 249 f. Tese (Doutorado em Educação) - Pontifícia Universidade Católica de São Paulo, São Paulo, 2010. (Tese)

RANGEL. Mary. A pesquisa de representação social no enfrentamento de problemas socioeducacionais. Aparecida, SP: Ideias e Letras, 2003. (Obra completa)

REVEL, Judith. Foucault: Conceitos essenciais. São Carlos: Clara Luz. 2005. (Obra Completa)

ROSA, Alexandre Morais da. A teoria dos jogos aplicada ao Processo Penal. $2^{\mathrm{a}}$ Ed. Empório do Direito e Rei dos Livros, 2015. (Obra Completa)

ROSALDO, Renato. Cultura y verdad la reconstrucción del análisis social. Trad. Jorge Gómez R. Quito: Abya-Yala, 2000. (Obra Completa)

SAFFIOTI, Heleieth. A discriminação de gênero e as diversas formas de violência contra a mulher. In: L. Q. Moraes \& R. Naves (Orgs.), Advocacia pro bono em defesa da mulher vítima de violência. Campinas: Unicamp (2002). p. 33-41 (Capitulo de Livro) 
Heleieth. O poder do macho. 6 ed. São Paulo: Moderna, 1987. (Coleção

Polêmica). (Obra Completa)

SCOTT, Joan. Gênero: uma categoria útil de análise histórica. In: Educação \& Realidade, v. 20, n. 2, jul./dez. 1995. p.71-99. (Artigo em periódico físico)

TELES, Maria Amélia de Almeida e MELO, Mônica de. O Que É Violência contra a Mulher. São Paulo: Brasiliense, 2003. (Coleção primeiros passos). (Obra Completa) 